\title{
Correction to: Attributes Used for Cancer Screening Discrete Choice Experiments: A Systematic Review
}

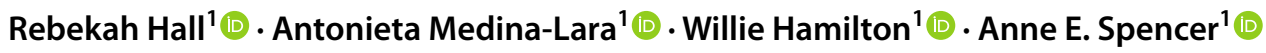

Published online: 12 November 2021

(c) The Author(s), under exclusive licence to Springer Nature Switzerland AG 2021

\section{Correction to: \\ The Patient - Patient-Centered Outcomes Research https://doi.org/10.1007/s40271-021-00559-3}

In this article Figure 2 data points were missing in the following rows (in all cases the missing data point is a green outlined circle with a dot in the centre ' $a$ '):

1. Row 4 (Gerard, et al. [30])—'sensitivity' column

2. Row 8 (Marshall, et al. [78])—'sensitivity' column

3. Row 11 (Marshall, et al. [41] — 'sensitivity' column
4. Row 15 (Pignone, et al. [42]) - 'mortality risk' column

5. Row 15 (Pignone, et al. [42]) — 'chance of cancer diagnosis' column

6. Row 17 (de Bekker-Grob [50])—'overtreatment/diagnosis' column

7. Row 22 (Brenner, et al [36] - 'mortality risk' column

8. Row 22 (Brenner, et al [36] - 'chance of cancer diagnosis' column

The figure should have appeared as shown below

The original article can be found online at https://doi.org/10.1007/ s40271-021-00559-3.

Rebekah Hall

rh591@exeter.ac.uk

1 College of Medicine and Health, University of Exeter, South Cloisters, St Luke's Campus, Heavitree, Exeter EX1 2LU, UK 


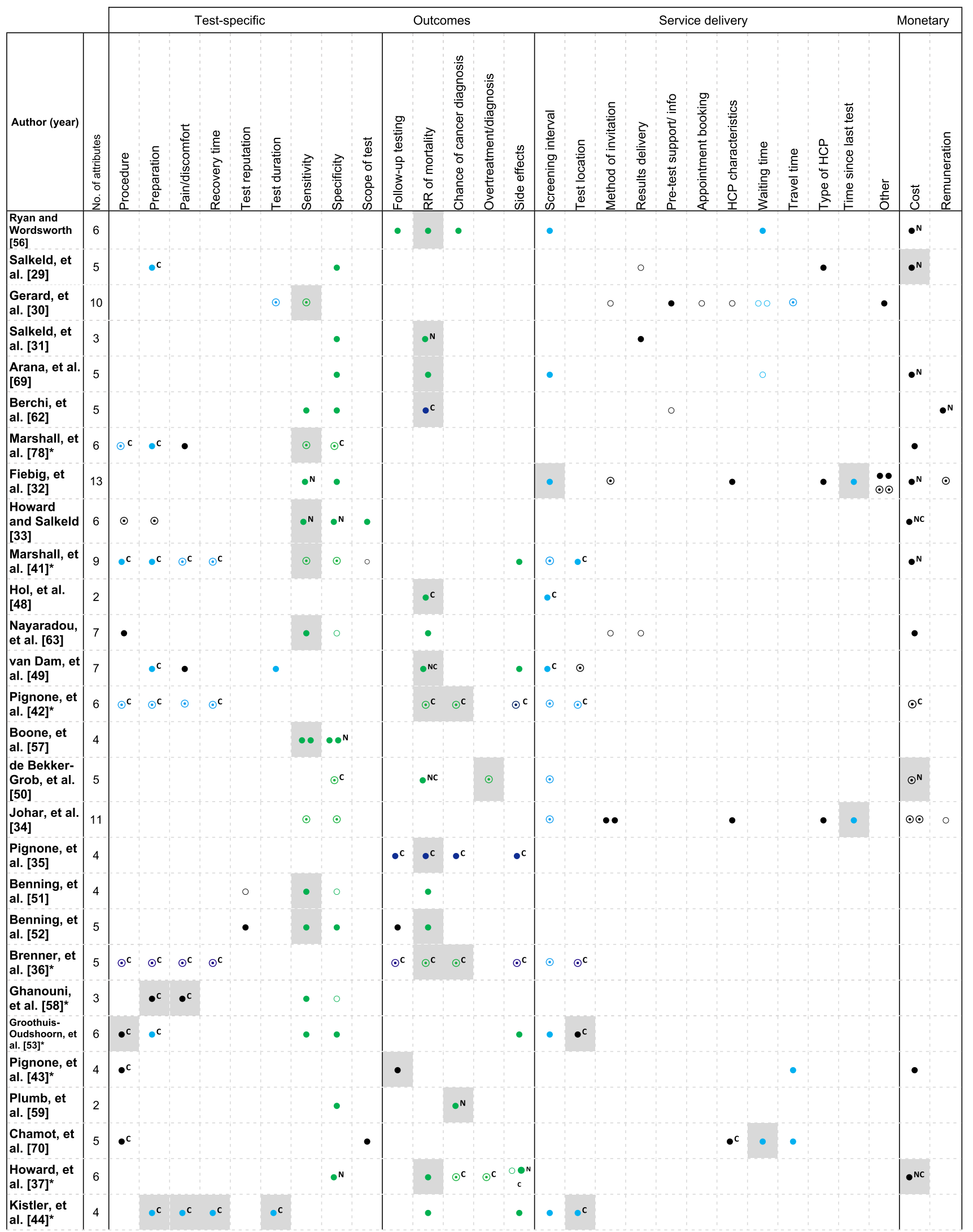




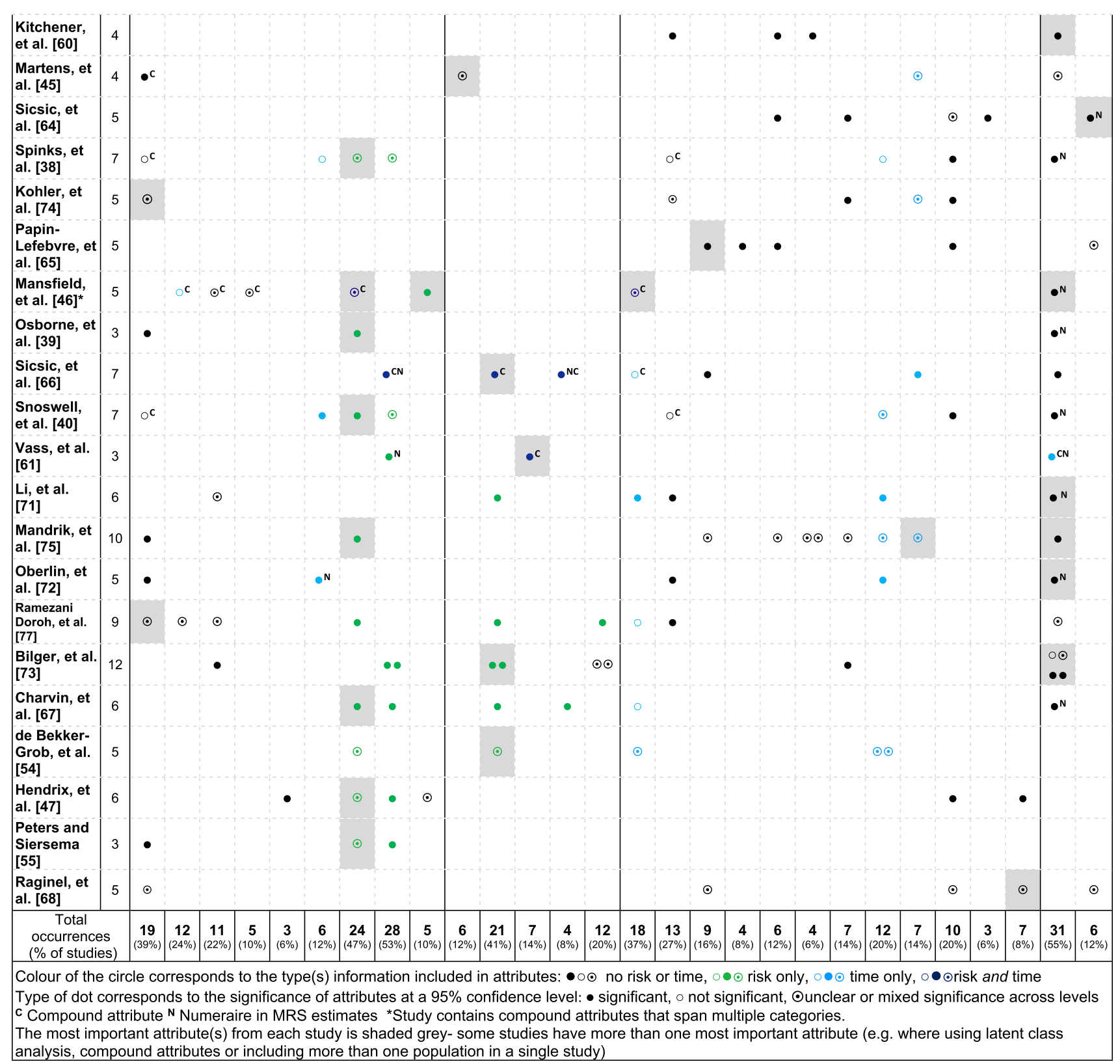

The original article has been corrected. 